\title{
Extreme endoscopy: direct jejunostomy, re-anastomosis of bowel, percutaneous assisted transprosthetic endoscopic drainage in Roux-en-Y gastric bypass
}

A 52-year-old female with history of Roux-en-Y gastric bypass underwent resection of a huge cystic tumor of the pancreas. Postoperatively an amylase-rich retroperitoneal fluid collection was noted. The patient was referred for doubleballoon endoscopic retrograde cholangiopancreatography (ERCP) for a suspected pancreatic duct leak. The patient had anemia, anasarca, and severe malnutrition (albumin level of $1.8 \mathrm{~g} / \mathrm{dl}$ - normal range 3.5 to $4.6 \mathrm{~g} / \mathrm{dl}$; hemoglobin $9 \mathrm{~g} / \mathrm{dl}$ - normal range 11.5 to 14.5$)$. During endoscopy performed under general anes- thesia, it became evident that the jejunal esophageal anastomosis was disrupted, communicating with a large pleuroperitoneal abscess. At this time a change in plans became mandatory.

First, a direct, double-balloon enteroscopy (DPE) jejunostomy was performed to secure nutritional support ( $\triangleright$ Fig. 1 , - Video 1). Second, a Guardus overtube (STERIS Endoscopy, Mentor, Ohio, USA) was inserted per-orally into the abscess cavity and the therapeutic gastroscope was passed numerous times to remove copious amounts of pus and food using extraction devices. Third, the disrupted bowel was re-anastomosed endoscopically using a fully covered self-expanding metal stent (FCSEMS) (Cook Medical, Bloomington, Indiana, USA). In order to prevent stent migration, an over-thescope clip was used to anchor the FCSEMS in the esophagus. And finally, percutaneous assisted transprosthetic endoscopic therapy with sponge insertion was used to drain the abscessed cavity ( $\vee$ Fig.1, \Video 1). Several sponge exchanges were performed through the stent to finally collapse the cavity. The
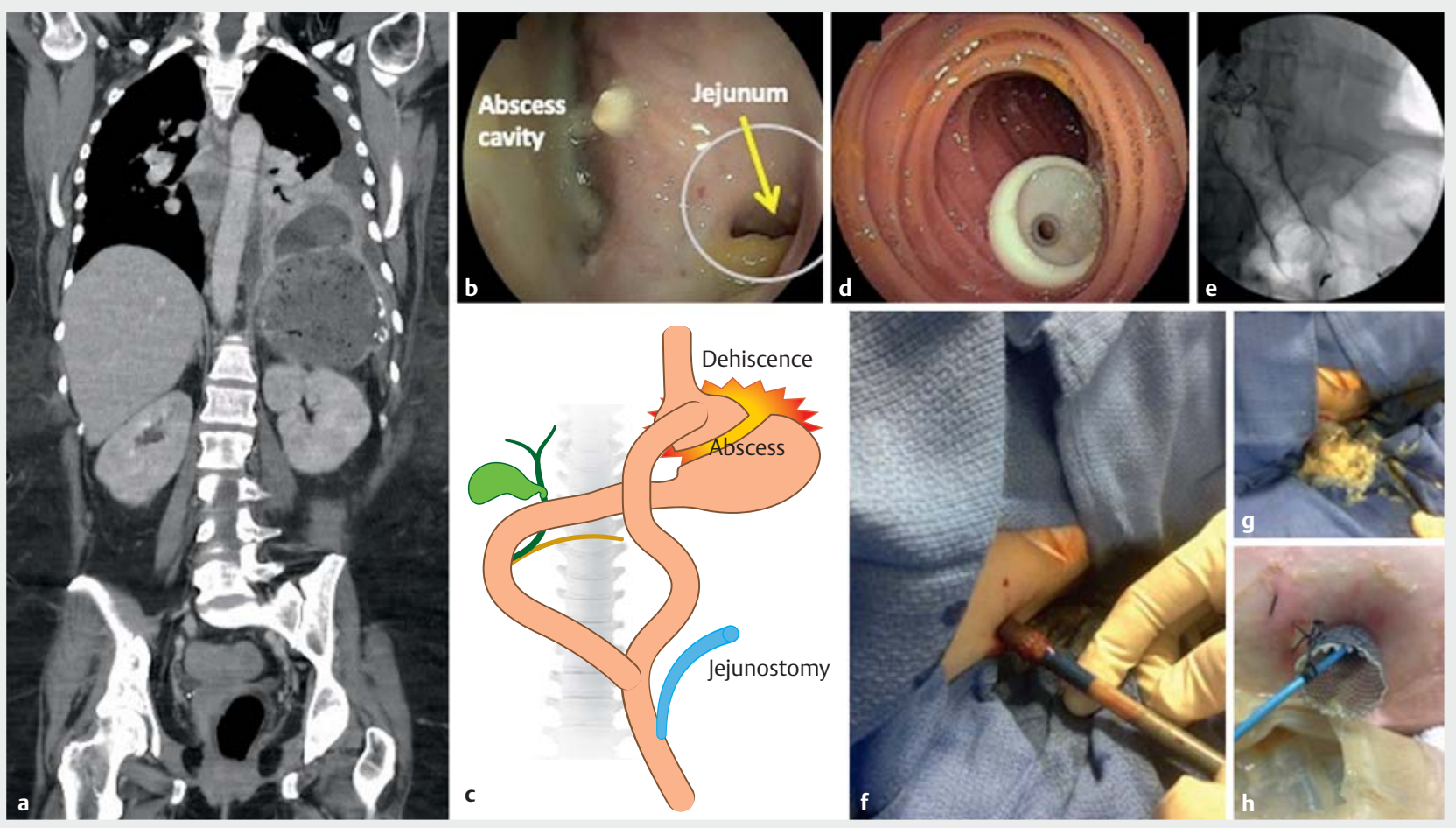

- Fig. 1 Disrupted gastrojejunal anastomosis communicating with a retroperitoneal cavity after resection of large mucinous cystic tumor of the pancreas. a Large retroperitoneal and pleural abscess. b Dehiscence of esophagojejunostomy and remaining jejunal lumen (circle and arrow). c Schematic of post-surgical Roux-en-Y anatomy, dehiscence of the esophagojejunal anastomosis, abscess and direct double-balloon enteroscopy jejunostomy. $\mathbf{d}$ Jejunostomy using double balloon enteroscopy technique. e Re-anastomosis of esophagus and jejunum using esophageal fully covered self-expanding metal stent (FCSEMS), then anchored with an $11 / 6 \mathrm{t}$ over-the-scope-clip. $\mathbf{f}$ Percutaneous assisted transprosthetic endoscopic therapy to drain huge cavity. First step was to dilate the tract with an esophageal dilation balloon up to $15 \mathrm{~mm}$, and then insert an esophageal FCSEMS. g Upon expansion of the FCSEMS, a large amount of debris and pus exited the pleura and peritoneum. $\mathbf{h}$ After percutaneous assisted transprosthetic endoscopic therapy, a Ligoury nasobiliary drain was advanced over a wire into the necrotic cavity across the FCSEMS. A sponge had been attached to the drain to perform endosponge vacuum therapy. 


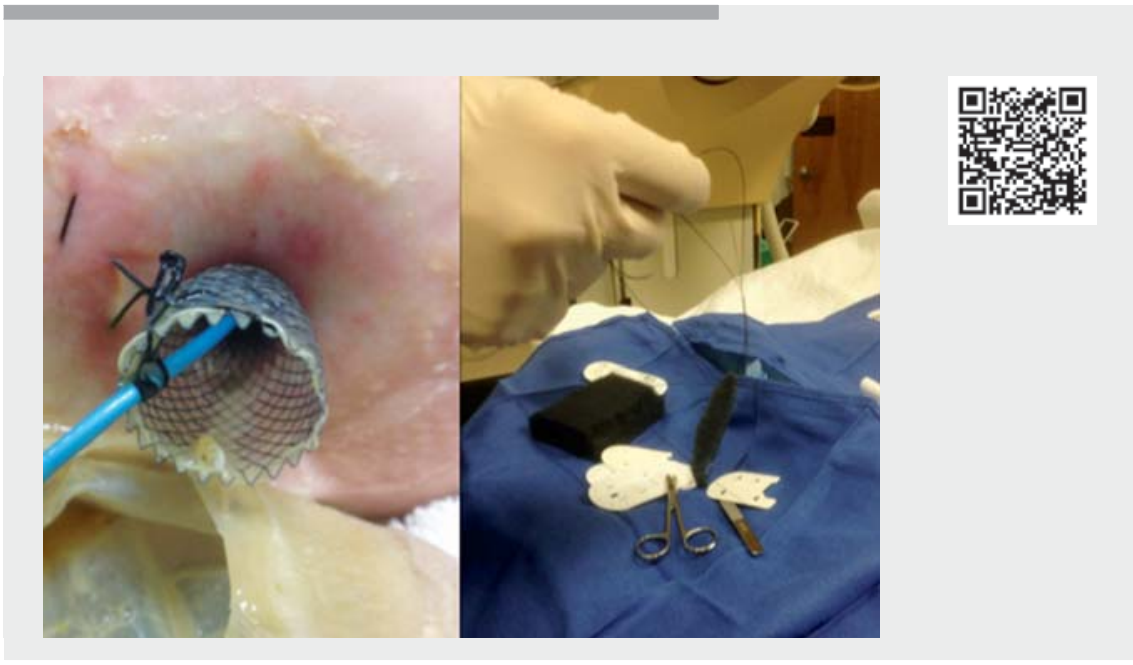

$\checkmark$ Video 1 Direct jejunostomy, re-anastomosis of bowel, and percutaneous assisted transprosthetic endoscopic therapy in patient with Roux-en-Y gastric bypass with retroperitoneal abscess.

stent used to perform the percutaneous assisted transprosthetic endoscopic therapy was removed after 4 weeks. At 2 months the esophagojejunal re-anastomosis FCSEMS was removed and the small remnant entero-pleural fistula was closed using an over-the-scope clip (12/6t, Ovesco, USA).

This case is an example of extreme endoscopy, where multiple endoscopes (enterooscope, therapeutic gastroscope, slim gastroscope), instruments, skills and techniques such as DPE jejunostomy [1], anchoring of FCSEMS [2], and percutaneous assisted transprosthetic endoscopic therapy [3] became mandatory to solve various complex post-operative adverse events in a poor surgical candidate, leading to complete resolution of the all life-threatening complications, including disrupted esophagojejunostomy, pleuroperitoneal abscess, abdominal sepsis, malnutrition and esophagopleural fistula.

Endoscopy_UCTN_Code_TTT_1AO_2AI

\section{Competing interests}

Klaus Mönkemüller has received honoraria from Cook Medical, USA and Ovesco, Tübingen, Germany, for giving academic lectures.

\section{References}

[1] Velázquez-Aviña J, Beyer R, Díaz-Tobar CP et al. New method of direct percutaneous endoscopic jejunostomy tube placement using balloon-assisted enteroscopy with fluoroscopy. Dig Endosc 2015; 27: 317-322

[2] Mudumbi S, Velazquez-Aviña J, Neumann $\mathrm{H}$ et al. Anchoring of self-expanding metal stents using the over-the-scope clip, and a technique for subsequent removal. Endoscopy 2014; 46: 1106-1109

[3] Law R, Wong Kee Song LM et al. Single-session ERCP in patients with previous Roux-en$Y$ gastric bypass using percutaneous-assisted transprosthetic endoscopic therapy: a case series. Endoscopy 2013; 45: 671-675

Bibliography

Endoscopy 2022; 54: E13-E14

DOI 10.1055/a-1346-7877

ISSN 0013-726X

published online 16.2.2021

(c) 2021. Thieme. All rights reserved.

Georg Thieme Verlag KG, Rüdigerstraße 14, 70469 Stuttgart, Germany

Álvaro Martínez-Alcalá García ${ }^{1,2}$ ๑, Ivan Jovanovic ${ }^{2,3}$, Ali M. Ahmed ${ }^{2}$, Marco

D’Assuncao ${ }^{4}$, Thomas Kröner ${ }^{5} \stackrel{\oplus}{\text {, Klaus }}$ Mönkemüller 2,3,6

1 Department of Gastroenterology, Hospital Universitario Infanta Leonor, Madrid, Spain

2 Basil I. Hirschowitz Endoscopic Center of Excellence, University of Alabama at Birmingham, Alabama, USA

3 University of Belgrade, Belgrade, Serbia

4 Department of Surgery, Hospital Sirio Libanes, Sao Paulo, Brasil

5 Division of Gastroenterology, Mayo Clinic, Jacksonville, USA

6 Department of Gastroenterology, Ameos Teaching University Hospital (Otto-vonGuericke University - Magdeburg), Halberstadt, Germany

\section{ENDOSCOPY E-VIDEOS}

https://eref.thieme.de/e-videos

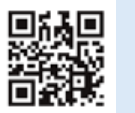

Endoscopy E-Videos is a free access online section, reporting on interesting cases and new techniques in gastroenterological endoscopy. All papers include a high quality video and all contributions are freely accessible online.

This section has its own submission website at https://mc.manuscriptcentral.com/e-videos
Corresponding author

\section{Klaus Mönkemüller, MD}

Director of Endoscopy, Division of Gastroenterology, University Teaching Hospital - Ameos Klinikum Halberstadt, Gleimstraße 5, 38820 Halberstadt, Germany moenkemueller@yahoo.com 